EPJ Web of Conferences 59, 18002 (2013)

DOI: $10.1051 /$ epjconf/20135918002

(C) Owned by the authors, published by EDP Sciences, 2013

\title{
Multi-keV X-ray sources from metal-lined cylindrical hohlraums
}

\author{
L. Jacquet ${ }^{\mathrm{a}}$, F. Girard, B. Villette, Ph. Stemmler and M. Primout
}

CEA, DAM, DIF, 91297 Arpajon, France

\begin{abstract}
In 2009 a series of metal-lined hohlraums were tested on the Omega laser facility. The main aims of the campaign were to improve our understanding of the multi-keV energy production and our capability to numerically reproduce the measured conversion efficiencies (CE's). Two studies have been primarily planned: the effect of the metallic plasma mean ionization states and that of hydrodynamics. Six targets were experimented for which the metallic materials (titanium, copper, germanium), the cavity diameter, and the irradiation energy were varied. Here we compare experimental and calculated results. The numerical simulations are performed with the 2D hydro-radiative code FCI2. For all the cavities, the measured multi$\mathrm{keV} \mathrm{x}$-ray powers versus time are qualitatively well reproduced by the simulations, indicating that hohlraum hydrodynamics seems to be well calculated. But we have an underestimation by a factor of $\sim 2$ for the calculated CEs versus experimental values for titanium and copper hohlraums. By contrast there is a good agreement between measurements and calculations for the germanium hohlraum. To explain these results, we have calculated off-line integrated emissivities for couples of $(\rho, \mathrm{Te})$ values contributing to the multi-keV production with several non-local-thermal-equilibrium (NLTE) atomic physics models.
\end{abstract}

\section{INTRODUCTION}

Multi-keV x-ray sources are required for diagnostics of inertial confinement fusion (ICF) experiments and material testing. In particular for ICF related phenomena, $\mathrm{x}$-ray imaging is an important technique to determine density, symmetry, size, interface, and opacity informations concerning high-density objects. Under-dense gaseous targets [1,2] obtained with gas-bags or gas can filled with argon, xenon or krypton, emit multi-keV $\mathrm{x}$-rays with a high laser to $\mathrm{x}$-ray conversion efficiency $(\mathrm{CE})$ but have restricted domains for accessible photon energies. Solid metallic targets [3] enable the creation of sources which span a wider photon energy range but have shown low CE's. To improve the CE's, new source principles have been considered as metal-doped aerogel targets [4,5], pre-pulsed thin metallic foils [6] and metal-lined hohlraums which are plastic cylinders coated with metallic materials. Two campaigns using titanium (Ti) and germanium (Ge) lined hohlraums were performed on Omega in 2005 and 2007 [7]. The results show systematic large discrepancies between measured and calculated CE's for the titanium targets [8]. A new campaign has been carried out in 2009 on Omega with the aim of studying and improving our capability to reproduce $\mathrm{x}$-ray production of such metal-lined sources with our numerical tools and physical models.

\section{TARGET DEFINITION, LASER PARAMETERS, AND MAIN DIAGNOSTICS}

Six targets were experimented, three Ti hohlraums, two copper $(\mathrm{Cu})$ hohlraums and one Ge hohlraum. The targets were $2.5 \mathrm{~mm}$ long and had a $1.6 \mathrm{~mm}$ plastic wall inner diameter except for one Ti target which had a larger diameter $(2.4 \mathrm{~mm})$. The plastic wall thickness was $100 \mu \mathrm{m}$. Five targets were fired

ae-mail: laurent.jacquet@cea.fr

This is an Open Access article distributed under the terms of the Creative Commons Attribution License 2.0, which permits unrestricted use, distribution, and reproduction in any medium, provided the original work is properly cited. 

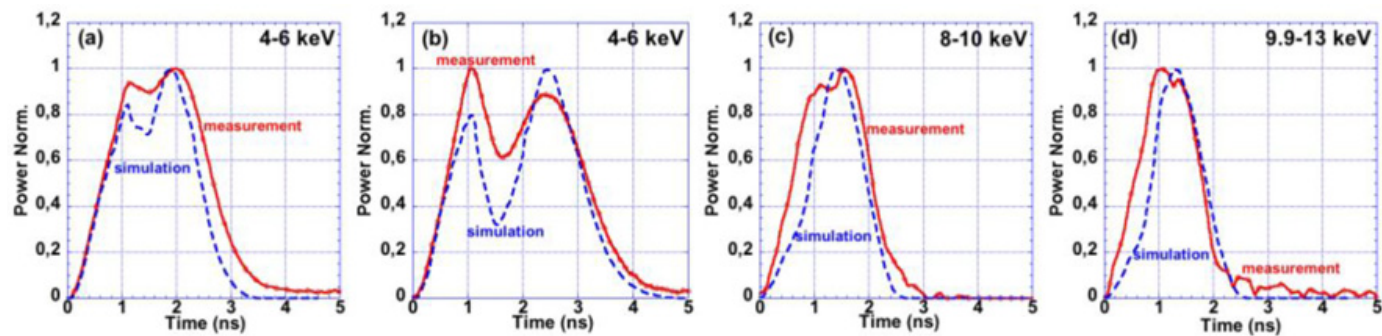

Figure 1. Normalized multi-keV x-ray powers for (a) the Ti hohlraum, (b) the Ti hohlraum of large diameter, (c) the $\mathrm{Cu}$ hohlraum, (d) the Ge hohlraum, as measured by DMX (plain curves) and as calculated with FCI2 (dashed curves). These four targets were illuminated by $\sim 13.5 \mathrm{~kJ}$.

with a $1 \mathrm{~ns}$ square pulse shape and a two-side irradiation using the $42^{\circ}$ and $59^{\circ}$ beam cones. The sixth target (a Ti hohlraum) was illuminated at reduced energy with only 5 beams per irradiation side. The source plasmas were looked by two broadband spectrometers from CEA, DMX [9] and micro-DMX, and two high-resolution spectrometers, time integrated and time resolved, HENWAY and SSCA. In addition, we had imaging systems, XRFC and XRPHC, to observe the x-ray emission volumes with and without temporal resolution.

\section{MULTI-KEV WAVEFORMS AND EMISSION ZONES}

The time-dependant multi-keV powers measured by DMX and calculated with the two-dimensional radiative code FCI2 [10] are given in Figure 1. The waveforms are plotted in arbitrary units and show a reasonably good qualitative agreement between measurements and simulation results. By postprocessing FCI2 results with the diagnostic code DIXIM [11], we show that the multi-keV power primarily comes from two zones, one located near the target wall and directly heated by the laser spots, and an other one located along the cylinder axis and due to the plasma ablated from the wall. For each target, the two contributions to the total power ("wall" contributions and "axis" contributions) are delayed in time. The delay decreases when the $\mathrm{Z}$ of the material increases and increases when the diameter cavity increases. So we can explain the shapes of the multi-keV waveforms. This gives us confidence in the capability of FCI2 to reproduce how these targets operate from the point of view of hydrodynamics.

\section{K-BAND X-RAY ENERGIES AND CONVERSION EFFICIENCIES}

As absolutely calibrated diagnostics, DMX and micro-DMX give the energies per unit solid angle emitted in the $\mathrm{Ti}, \mathrm{Cu}$ and $\mathrm{Ge} \mathrm{K}$-shell bands. We can then extrapolate these results to whole space $(4 \pi$ sr) and calculate the CE's. These energy outputs and CE's are presented in Table 1 and Table 2 along with the simulation results obtained with FCI2. The energies and CE's derived from FCI2 calculations are underestimated by factors of $\sim 1.9-2.75$ (Ti targets) and $\sim 1.8-2$ (Cu targets) from the experimental values. By contrast, for the Ge target we have a good agreement between measurements and calculations. These comparison results between experiments and simulations are similar to that obtained for the Ti and Ge targets fired during the 2005 and 2007 campaigns on Omega.

\section{PLASMA IONIZATION STATES AND EFFECTS OF NLTE MODELS}

The spectra recorded by the HENWAY spectrometer give detailed structures of K-shell emission lines for $\mathrm{Ti}, \mathrm{Cu}$, and $\mathrm{Ge}$ target plasmas. For the Ti target illuminated by 30 beams, He- $\alpha$ and $\mathrm{Ly}-\alpha$ emission 
IFSA 2011

Table 1. Multi-keV energy outputs and CEs as measured by DMX and as calculated with FCI2.

\begin{tabular}{|l|c|c|c|c|}
\hline Target type & $\begin{array}{c}\text { exp energy } \\
(\mathrm{J} / \mathrm{sr})( \pm 20 \%)\end{array}$ & $\begin{array}{c}\text { calc energy } \\
\text { FCI2 (J/sr) }\end{array}$ & $\begin{array}{c}\text { CE in } 4 \pi \\
\exp (\%)\end{array}$ & $\begin{array}{c}\text { CE in } 4 \pi \\
\text { FCI2 }(\%)\end{array}$ \\
\hline $\begin{array}{l}\text { Ti nominal } \\
30 \text { beams }\end{array}$ & 58 & 30.7 & 5.4 & 3.2 \\
\hline $\begin{array}{l}\text { Ti nominal } \\
10 \text { beams }\end{array}$ & 10 & 5.4 & 2.8 & 1.6 \\
\hline $\begin{array}{l}\text { Ti largediam } \\
30 \text { beams }\end{array}$ & 61 & 32.5 & 5.6 & 2.8 \\
\hline $\begin{array}{l}\text { Genominal } \\
30 \text { beams }\end{array}$ & 5.5 & 4.1 & 0.5 & 0.41 \\
\hline
\end{tabular}

Table 2. Multi-keV energy outputs and CEs as measured by micro-DMX and as calculated with FCI2.

\begin{tabular}{|l|c|c|c|c|}
\hline Target type & $\begin{array}{c}\text { exp energy } \\
(\mathrm{J} / \mathrm{sr})( \pm 20 \%)\end{array}$ & $\begin{array}{c}\text { calc energy } \\
\text { FCI2 (J/sr) }\end{array}$ & $\begin{array}{c}\text { CE in 4 } \\
\exp (\%)\end{array}$ & $\begin{array}{c}\text { CE in } 4 \pi \\
\text { FCI2 }(\%)\end{array}$ \\
\hline $\begin{array}{l}\text { Ti nominal } \\
30 \text { beams }\end{array}$ & 88 & 34 & 8.2 & 3.2 \\
\hline $\begin{array}{l}\text { Ti nominal } \\
10 \text { beams }\end{array}$ & 15.6 & 6 & 4.4 & 1.6 \\
\hline $\begin{array}{l}\text { Ti largediam } \\
30 \text { beams }\end{array}$ & 71 & 27.4 & 7.2 & 2.8 \\
\hline $\begin{array}{l}\text { Genominal } \\
30 \text { beams }\end{array}$ & 5.4 & 5.3 & 0.48 & 0.47 \\
\hline $\begin{array}{l}\text { Gu nominal } \\
30 \text { beams }\end{array}$ & 22 & 12.3 & 2.1 & 1.1 \\
\hline $\begin{array}{l}\text { Gu nominal } \\
30 \text { beams }\end{array}$ & 23 & 12.3 & 2.2 & 1.1 \\
\hline
\end{tabular}

lines are strongly excited showing that both He-like and H-like ionization states were present in the plasma. For the Ti target irradiated by only 10 beams, the Ly- $\alpha$ line is still visible but the energy yield Ly- $\alpha / \mathrm{He}-\alpha$ is strongly reduced indicating that the $\mathrm{H}$-like ion fraction is also clearly reduced. But the discrepancy between measured and calculated CE's is as well $\sim 2$ for this target. In both $\mathrm{Cu}$ and $\mathrm{Ge}$ spectra, only He-like lines are visible showing that the He-like ionisation states is dominant in the multi$\mathrm{keV}$ emission zones. The simple consideration of mean plasma ionization states is then not sufficient to explain the simulation-versus-measurement discrepancies. To assess the effects of NLTE treatment we have performed off-line emissivity calculations with several NLTE models: RADIOM [12], NOHEL [13], and FLYCHK [14]. NOHEL data can be computed without (NOHEL1) or with (NOHEL2) the twoelectron processes (self-ionization and dielectronic recombination) taken into account. Figure 2 shows the integrated emissivities as a function of the electronic temperature (Te) for a fixed plasma density $0.01 \mathrm{~g} / \mathrm{cc}$. Emissivity spectra are integrated over the multi-keV spectral $\mathrm{K}$ bandwidths of $\mathrm{Ti}, \mathrm{Cu}$, and $\mathrm{Ge}$. 


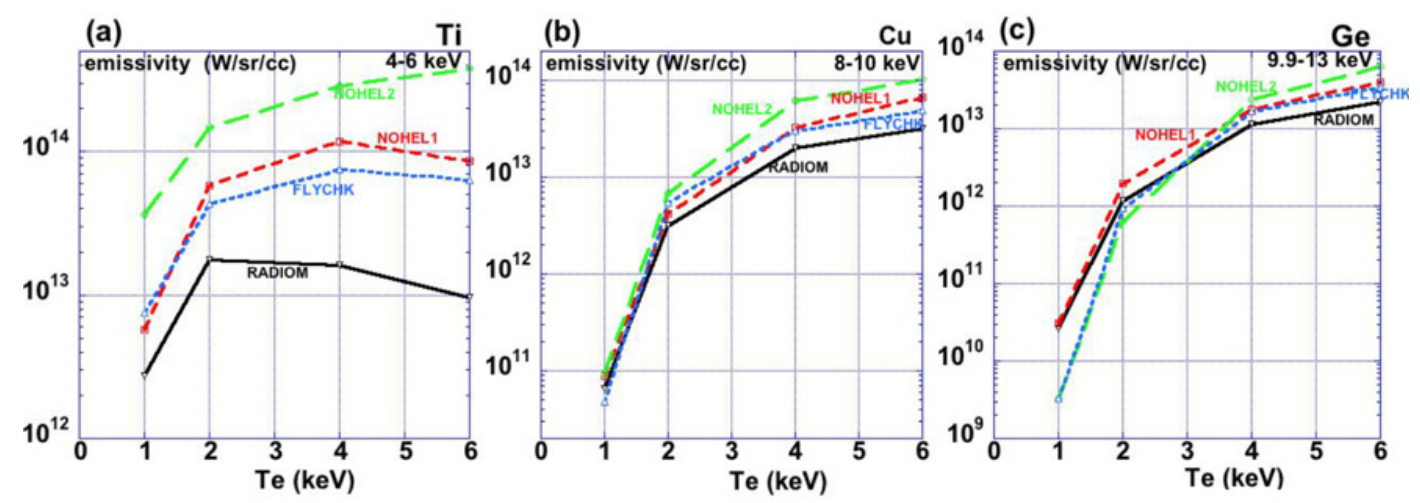

Figure 2. Integrated emissivities versus Te as computed by RADIOM (plain curves), NOHEL (dashed and longdashed curves), FLYCHK (dotted curves), for (a) Ti, (b) $\mathrm{Cu}$, and (c) Ge. The plasma density is $0.01 \mathrm{~g} / \mathrm{cc}$, the radiation temperature is $150 \mathrm{eV}$ and the integration spectral bandwiths are $4-6 \mathrm{keV}, 8-10 \mathrm{keV}$, and 9.9-13 keV.

In the optimal Te domain to get a good multi-keV production $(\sim 2-4 \mathrm{keV}), \mathrm{RADIOM}$ underestimates the emissivities with respect to the other models, the discrepancies being stronger for Ti; conversely, there is a rather good agreement between all the models in the case of $\mathrm{Ge}$. As we observe similar trends for two other plasma densities $(0.005 \mathrm{~g} / \mathrm{cc}$ and $0.02 \mathrm{~g} / \mathrm{cc})$, we feel that this comparison between several NLTE models give us an interesting clue for understanding the differences between measured and calculated emission for the $\mathrm{Ti}$ and $\mathrm{Cu}$ cavities. NLTE physics modelling seems to be essential for computing multikeV CE's of metal-lined sources and, more generally, of under-dense hot metallic plasmas.

\section{CONCLUSION}

We have successfully tested a new series of metal-lined cavities on Omega in 2009. A rather good qualitative agreement is obtained between diagnostic data and simulation results for time-dependant $\mathrm{x}$-ray powers and images, indicating that the cavity hydrodynamics seems to be well calculated. But we observe a systematic underestimation of the conversion efficiencies as calculated by FCI2 from the experimental values for $\mathrm{Ti}$ and $\mathrm{Cu}$ cavities and a good agreement for the $\mathrm{Ge}$ one. That confirms the results of previous campaigns for $\mathrm{Ti}$ and $\mathrm{Ge}$. We have calculated off-line emissivities integrated over the multi-keV spectral windows with several NLTE atomic physics models. We find that, in the $\mathrm{x}$-ray production thermodynamic domain, RADIOM underestimates the emissivities for $\mathrm{Ti}$ and $\mathrm{Cu}$ compared to the other models, and conversely, is in a rather good agreement for Ge. Then we infer that NLTE physics modelling effect is an attractive way to explain the remaining discrepancies between experimental measurements and simulation results for these shots.

\section{References}

[1] C.A. Back et al., Phys. Plasmas 10, 2047 (2003)

[2] K. B. Fournier et al., Phys. Plasmas 17, 082701 (2010)

[3] J. Workman and G. Kyrala, Rev. Sci. Instrument. 72, 678 (2001)

[4] K. B. Fournier et al., Phys. Rev. Lett. 92, 165005-1 (2004)

[5] K. B. Fournier et al., Phys. Plasmas 16, 052703 (2009)

[6] D. Babonneau et al., Phys. Plasmas 15, 092702 (2008)

[7] F. Girard et al., Phys. Plasmas 16, 052704 (2009)

[8] M. Primout et al ., J. Phys.: Conf. Ser. 112, 042051 (2008) 


\section{IFSA 2011}

[9] J. L. Bourgade et al., Rev. Sci. Instrum. 72, 1173 (2001)

[10] E. Buresi et al., Laser Part. Beams 4, 531 (1986)

[11] G. Schurtz et al., Phys. Plasmas 7, 4238 (2000)

[12] M. Busquet, Phys. Fluids. B 5, 419 (1993)

[13] C. Bowen, A. Decoster et al., J. Quant. Spectrosc. Radiat. Transf. 81, 71 (2003)

[14] H. K. Chung et al., High Energy Density Phys. 1, 3 (2005) 